Swarthmore College

Works

1996

\title{
Metaphor And Monophony In The Twentieth-Century Psychology Of Emotions
}

Kenneth J. Gergen

Swarthmore College, kgergen1@swarthmore.edu

Follow this and additional works at: https://works.swarthmore.edu/fac-psychology

Part of the Psychology Commons

Let us know how access to these works benefits you

\section{Recommended Citation}

Kenneth J. Gergen. (1996). "Metaphor And Monophony In The Twentieth-Century Psychology Of

Emotions". Historical Dimensions Of Psychological Discourse. 60-82. DOI: 10.1017/

CB09780511571329.004

https://works.swarthmore.edu/fac-psychology/843

This work is brought to you for free by Swarthmore College Libraries' Works. It has been accepted for inclusion in Psychology Faculty Works by an authorized administrator of Works. For more information, please contact myworks@swarthmore.edu. 


\section{$4 \quad$ Metaphor and monophony in the twentieth-century psychology of emotions}

Kenneth J. Gergen

Attempts to define the emotions and elucidate their character have ornamented the intellectual landscape for over two thousand years. Two characteristics of this continuing colloquy are particularly noteworthy: first, the presumption of palpability and, second, the interminability of debate. In the former case, until the present century there has been little doubting the obdurate existence of the emotions. In the second book of the Rhetoric, Aristotle distinguished among 15 emotional states; Aquinas's Summa Theologiae enumerated 6 "affective" and 5 "spirited" emotions; Descartes distinguished among 6 primary passions of the soul; the eighteenth-century moralist, David Hartley, located 10 "general passions of human nature"; and the major contributions by recent theorists, Tomkins (1962) and Izard (1977), describe some 10 distinctive emotional states. In effect, the cultural history is one in which there is unflinching agreement regarding the palpable presence of emotional states within persons.

At the same time, these deep ontological commitments are also matched by a virtual cacophony of competing views on the character of the emotions - their distinguishing characteristics, origins, manifestations, and significance in human affairs. For Aristotle the emotions constituted "motions of the soul"; for Aquinas the emotions were experienced by the soul, but were the products of sensory appetites; Descartes isolated specific "passions of the soul," these owing to movements of the "animal spirits" agitating the brain. For Thomas Hobbes (1651), the passions were constitutive of human nature itself, and furnished the activating "spirit" for the intellect, the will, and moral character. In his Treatise on Human Nature (1739), David Hume divided the passions into those directly derived from human instinct (e.g., the desire to punish our enemies) and those which derive from a "double relation" of sensory impressions and ideas. A century later, both Spencer's Principles of Psychology and Darwin's The Expression of the

I wish to thank David Schaub and Rebeckah Flowers for their valuable assistance in this research, and the William Fulbright Foundation, Washington, DC, and Fundacion Interfas, Buenos Aires, for making the funds and facilities available for its completion. An earlier draft of the present paper appears in History of the Human Sciences, 1995, 8, 1-23. 
Emotions in Man and Animals attempted to place the emotions on more seemingly certain biological grounds.

This interminability of debate is most effectively illustrated by considering the "objects of study" themselves, that which is identified as an emotion. For example, Aristotle identified placability, confidence, benevolence, churlishness, resentment, emulation, longing, and enthusiasm as emotional states no less transparent than anger or joy. Yet, in their twentieth-century exegeses, neither Tomkins (1962) nor Izard (1977) recognizes these states as constituents of the emotional domain. Aquinas believed love, desire, hope, and courage were all central emotions, and, while Aristotle agreed in the case of love, all such states go virtually unrecognized in the recent theories of Tomkins and Izard. Hobbes identified covetousness, luxury, curiosity, ambition, good naturedness, superstition, and will as emotional states, none of which qualify as such in contemporary psychology. Tomkins and Izard agree that surprise is an emotion, a belief that would indeed puzzle most of their predecessors. However, where Izard believes sadness and guilt are major emotions, they fail to qualify in Tomkins analysis; simultaneously, Tomkins sees distress as a central emotion, where Izard does not.

There is a certain irony inhering in these two features of emotional debate - palpability and interminability. If the emotions are simply there as transparent features of human existence, why should univocality be so difficult to achieve? Broad agreement exists within scientific communities concerning, for example, chemical tables, genetic constitution, and the movements of the planets; and where disagreements have developed, procedures have also been located for pressing the nomenclature toward greater uniformity. Why, then, is scientific convergence so elusive in the case of emotions? At least one significant reason for the continuous contention derives from a presumptive fallacy, namely Whitehead's fallacy of misplaced concreteness. One suspects that we labor in a tradition in which we mistakenly treat the putative objects of our mental vocabulary as palpable, where it is the names themselves that possess more indubitable properties. Because there are words such as love, anger, and guilt, we presume that there must be specific states to which they refer. And if there are not, we presume that continued study of the matter will set the matter straight. Two thousand years have been insufficient to achieve this end, and one is ineluctably led to suppose that there are no such isolable conditions inside individuals to which such terms refer (or at a minimum, the terms are not determinant markers of such states).

This latter possibility has become far more reasonable within recent years, and particularly with the development of ordinary language philosophy. Wittgenstein's Philosophical Investigations was the major stimulus in this case, both questioning the referential base for mental predicates and 
offering an alternative way of accounting for such discourse. As Wittgenstein (1980) asks, "I give notice that I am afraid. - Do I recall my thoughts of the past half hour in order to do that, or do I let a thought of the dentist quickly cross my mind in order to see how it affects me; or can I be uncertain of whether it is really fear of the dentists, and not some other physical feeling of discomfort?" (p. 32e). The impossibility of answering such a question in terms of mental referents for emotion terms demands an alternative means of understanding mental terms. This understanding is largely to be found in Wittgenstein's arguments for use-derived meaning. On this view, mental predicates acquire their meaning through various language games embedded within cultural forms of life. Mental language is rendered significant not by virtue of its capacity to reveal, mark, or describe mental states, but from its function in social interchange. The challenge posed by these ideas to traditional dualistic theories of knowledge was effectively extended in the works of Ryle (1949) and Austin (1962). Other scholars, such as Kenny (1963) and Anscombe (1976), went on to explore the various functions, problems, and philosophical challenges of mental state terms in their everyday usage.

As the Wittgensteinian view is extended, the possibility of falsifying scientific propositions about emotional states becomes increasingly problematic (see Gergen, 1994). This problematization is fortified by a substantial body of writing in both the history of science and the sociology of knowledge, demonstrating the sociocultural processes at work in rendering various scientific claims intelligible and acceptable. The important point for the present offering is that together these various arguments invite consideration of the reality posits of scientific psychology, independent of the methods and findings typically employed as justificatory bases within the field. It is within this context that I wish, then, to sketch with broad strokes the vicissitudes of emotional discourse in scientific psychology of the present century. As I shall propose, emotion terms have largely served political purposes within professional psychology, strategically situating the discipline (or its various subcultures) in relationship to the academy, to the general public, and to its own membership. What psychology has had to say about the emotions, or in many instances failed to say, is not - and in principle cannot be - the result of careful and controlled observation. Rather its varying scientific postures can be traced, in large measure, to the intellectual and cultural circumstances in which professional life is played out.

Caveats are required: I am not proposing that the present account is conclusive. This is but a preliminary sketch, and there are many other influences to which inquiry should also be directed. Nor am I proposing that all inquiry into the emotions is the result of consciously considered strategies. Rather, I am generating a lens through which coherent sense may be 
derived from an otherwise chaotic morass of particulars. Finally, the present analysis is largely confined to developments in mainstream psychology in the United States. There are other stories to be told about the development of psychology in the context of an embattled Europe, and as well in the many tributaries of American psychology.

\section{Prolegomenon on power/knowledge}

Foucault's $(1978,1979)$ writings on knowledge and power are an effective entry to the present analysis. Language, for Foucault, serves as a major medium for carrying out relations. Because language constitutes what we take to be the world, and rationalizes the form of reality thus created, it also serves as a socially binding force. By acting within language, relations of power and privilege are sustained. And, by engaging in the further circulation of a form of language, the array of power relations is further extended. Thus, as disciplines such as psychology, psychiatry, and sociology are developed, so do they operate as discursive regimes. They specify a world and a normative domain of relevant action. As these languages are further elaborated and disseminated, so then is the configuration of power extended. In this sense, power relations possess a productive capacity. The relevance of this perspective for psychology has been effectively demonstrated in Rose's $(1985,1990)$ analyses of psychological theory and measurement as forms of cultural control.

Yet, there is a strong tendency in Foucault's work to treat discursive regimes as unitary forms. That is, regimes tend to be treated as internally coherent and hegemonically accelerated. As Foucault (1979) proposes, beginning in the eighteenth century and extending into the present,

the formation of knowledge and the increase of power regularly reinforce(d) one another in a circular process. . . . First the hospital, then the school, then, later the workshop were not simply "reordered" by the disciplines: they became, thanks to them, apparatuses such that any mechanism of objectification could be used in them as an instrument of subjection, and any growth of power could give rise in them to possible branches of knowledge; it was this link, proper to the technological system that made possible within the disciplinary element the formation of clinical medicine, psychiatry, child psychology, educational psychology, and the rationalization of labor. It is . . . a multiplication of the effects of power through the formation and accumulation of new forms of knowledge. (p. 224)

This line of argument has also been fortified by much Marxist theory, particularly as inspired by Althusser, of a unified, hegemonic order.

The view I wish to propose, and indeed which might be supported with alternative quotes from Foucault's capillary view of power, is that life within what we take to be the existing regimes is seldom unitary. Rather, regimes themselves are composed of variegated discursive practices, drawn from sundry contexts, ripped from previous ecologies of usage and stitched 
awkwardly together to form what - with continued usage and considerable suppression - is seen as a coherent view ("a discipline"). Ontologies and rationalities are thus only apparently and momentarily univocal; they harbor multiple tensions and contradictions even for those who dwell within. In a sense, I wish to augment (or shift the emphasis of) a Foucauldian perspective with important theses from Bakhtin (1981) and Derrida (1976). While Bakhtin points to the hybrid or heteroglossial character of any given domain of language, Derrida's writings emphasize the failure of any language to carry autonomous meanings - to stand independent of its multiple signifying traces. The present analysis agrees, then, with Raymond Williams's (1980) view that "Hegemony is not singular. Its own internal structures are highly complex, and have continually to be renewed, recreated and defended; and by the same token ... they can be continually challenged and in certain respects modified" (p. 38). The present concern is the history of these internal movements in psychological science - their challenges, conflicts and evolutions - from the prebehaviorist period through contemporary constructionism.

\section{Metaphor and the politics of emotion}

The status of psychological study at the turn of the century was a tenuous one. Scholars both in Europe and the United States were struggling to achieve recognition for a uniquely psychological science, independent of its philosophic forbears, and independent of adjoining and already established sciences (particularly medicine and biology). At the same time, if such a discipline were to achieve sanction within the academy, its rationale would have to achieve intelligibility in these very disciplines, as in others. Moreover, such a discipline should ideally enjoy the affirmation of a broader, educated public. This was particularly so in the United States, with its strong emphasis on the pragmatic outcomes of scholarly work (Manicas, 1987). In terms of the present analysis, the central challenge for psychology, then, was to generate forms of self-representation that could simultaneously appeal to audiences both within the academy and the educated public - in addition to its own membership.

It is within this context that we may consider the status of emotions discourse. At the outset, such discourse serves as symbolic capital of high order. Given the long history of scholarship on the emotions, particularly within philosophy and later in medicine and biology, there was little doubting the existence of emotions in human makeup. And, for the fledgling discipline to claim independent, but allied, investigation into the emotions would be a potentially powerful self-justificatory device. Similarly, because of long-standing beliefs in the emotions more generally within the culture, a discipline that could finally illuminate their character and function would 
purchase promise in providing useful information and services to the society.

At the same time, to annex the discourse of emotions was not without its dangers. Strong claims to probity on matters of the emotion could threaten the investments of the more established disciplines, thus fostering political enmity. Further, for psychology to employ the established forms of description and explanation could simultaneously threaten its claims to being a separate or independent discipline. In addition to these problems, emotions discourse also served as the mainstay for cultural romanticism. The romanticist rhetoric was becoming increasingly suspect - not only in certain sectors of philosophy, but within the sciences more generally. For a discipline aspiring to scientific status to grant the emotions a central place in its vocabulary of explanation could be hazardous. In effect, there were treasures to be gained in appropriating the discourse of the emotions, but the course could be perilous.

There was extant a rich and compelling vocabulary on which psychological investigation could proceed. Of particular importance, Averill (1990) distinguishes among five major metaphors available to psychological science from preceding centuries of dialogue: emotions as (1) inner feelings (experiences), (2) physiological responses, (3) animal impulses in human nature, (4) diseases of the mind, and (5) driving forces (vital energy). The metaphors were also wedded to estimable traditions. First, the nineteenthcentury writings of Bain, Darwin, and Spencer, among others, defined the emotions as biological processes (drawing from the related metaphors of emotions as physiological responses, and as animal impulses in human nature). The biological view was advantageous for a fledgling discipline, inasmuch as it would ally psychological study with the Naturwissenschaften as opposed to the new and more tentative breed of the Geisteswissenschaften. In contrast, there was also a long heritage - drawing from the works of Descartes, Hartley, and Cabanis - that defined the emotions largely in terms of internal sensations (the metaphor of inner feelings). It is this tradition that lent strong support to the efforts of nineteenth-century German psychologists to establish psychology as a science sui generis. For figures such as Fechner, Lehmann, Wundt, and Hamilton, the primary emphasis was thus placed on the emotions as elements of conscious experience.

Finally, a third tradition - more allied to the artistic community than to the biological and philosophical - granted the emotions a preeminent position in human makeup. This, the romanticist tradition, treated the emotions as the fundamental wellsprings for human action. For them these sources of energy were beyond the penetration by (mere) conscious sensation or reasoning. This was essentially the tradition of Goethe, Herder, and Nietzsche, and of Shelley, Keats, and Byron. It was also a tradition of 
special promise to practitioners of psychology, to those who functioned not in the impersonal conditions of the laboratory, but in the hospital or consultation room. For this was preeminently a tradition broadly shared within the culture. To speak this language would be most effective in the public sphere.

Faced with these options, how should the discipline proceed? In a broad sense, the choice was between a monophonic and a polyphonic intelligibility. In the former instance, one could select a single metaphor from the available array and, within the theoretical and research contexts, extend its intelligibility to full fruition. There were both advantages and liabilities in doing so. Each of the existing metaphors offered a major means of rendering an emotional world intelligible, and the full expansion of its linguistic implicature offered the possibility of a complete, coherent, and rhetorically powerful theory. Further, an effective monophonic account would either denigrate the significance of the alternatives, appropriate them, or fully erase their ontologies. For example, a theory that claims the emotions fundamentally to be inner feelings, can place physiology in a secondary position (as mere accompaniment or a reductionist parallel), and can function unproblematically without reference to impulses, diseases, or driving forces. Similarly, with the full expansion of the physiological metaphor, "feelings" become either a secondary manifestation or fully suspect; animal impulses can be appropriated as physiology at an imprecise level of description, and the metaphor of driving force becomes so much poetry. The driving-force theorist can reduce feelings and physiology to the status of manifestations of the driving force, can claim such discourses to be reductionistic (and largely irrelevant) descriptions, and can claim fully explanatory potential without reference to animal impulses.

Yet, the monophonic account is also purchased at a price. For psychology to lay claim to either the physiological or biological metaphors would encroach on neighboring disciplines and disclaim rights to independent status. The disease metaphor is highly circumscribed, and the driving force metaphor would ally the field too closely with romanticism. The metaphor of inner feelings had been particularly appealing in establishing psychology as an independent discipline in the German context. However, such a metaphor reduces psychology to the study of conscious states, and thus in the American context failed to meet the standards of pragmatic utility. If the field is to appeal to other disciplines without encroaching on their selfdefinitions, and if it is to acquire credibility both within and outside the academy, the more favorable choice would seem to be polyphony. That is, the most rhetorically powerful discourse should be one that harbors multiple metaphors. Whether this is indeed a winning option is revealed in the following. 


\section{The early impulse toward polyphony}

At the turn of the century, psychology as an academic discipline in the United States was struggling toward recognition. The American Psychological Association was organized in 1892 with 31 members, only a minority of whom identified themselves professionally as psychologists. If such a field was to justify itself through its accounts of mental life, how was it to proceed? From the preceding, there is much to be gained by appropriating the discourse of emotion; and there is more to be gained in this early stage by amalgamating metaphors than in monophony. Polyphonic models were also available for the undertaking. Within the immediately preceding decades, Lotze and Fechner in Germany and Lange in Denmark had attempted to integrate mind and body into a single theory of emotion. For each, there was an interactive relationship between the mind as sensorium and determinantly linked physiological processes; for each, psychological and biological inquiry were interdependent. For American psychology, William James's work was thus of pivotal significance. Not only did his $\mathbf{1 8 9 0}$ treatise, The Principles of Psychology, suggest the contours of a unified discipline - a mutually fortifying synthesis - but his theory of emotion demonstrated the possibility by integrating two of the root metaphors into a single formulation. Consider the famous passage:

Bodily changes follow directly the perception of the exciting fact and . . . our feeling of the same changes as they occur is the emotion. Common sense says we lose our fortune, are sorry and weep; we meet a bear, are frightened and run.... The hypothesis here to be defended says that this order of sequence is incorrect. . . . (Rather) we feel sorry because we cry, afraid because we tremble. (pp. 449-450)

As is clear, the emotions are the by-product of two interacting conditions, a biological event on the one side, and a pattern of sensations on the other. In effect, James linked the discourses of physical and sensory reality in such a way that emotional life could not be understood by a more reductionistic discipline. Both were required. One could surmise, then, the possibility of a unified psychology, a discipline requiring its own identity outside biology, but safely allied with this more established tradition.

But would it be possible to forge a second alliance, this time with the more pragmatically promising enterprise of clinical treatment? There were hopes extant even in 1896, with the development of the first psychological clinic at the University of Pennsylvania, that clinical practitioners could be integrated into a unified psychology. However, there were at least two major hurdles to be traversed. First, strongly committed to psychoanalytic theory, psychiatric practitioners were struggling to gain their own identity and public sanction. The practitioners in this case were also medical doctors as opposed to laboratory researchers. In effect, psychologists confronted 
an alterior subculture with its own centripetal force. Both related to and rationalizing these sociopolitical barriers, were discursive differences - primary among them the root metaphors for describing the emotions. The psychiatric view of emotions as life forces and the practices associated with this metaphor were not easily integrated into the biosensory formulations of the experimentalist. However, with some hope of integration, Sigmund Freud was invited in 1908 to speak to an estimable group of American psychologists. And in 1918 Robert Woodworth's Dynamic Psychology was published, a volume that attempted to integrate the psychodynamic views into the experimental account.

Yet, these were indeed uneasy alliances, for each attempt to integrate, collate, or combine necessarily left significant traces of the root metaphors. The extended discourse surrounding, substantiating, and constituting the metaphoric center remained undigested. The result was a continuous tension: By reverting to monophony, any subculture could brandish Occam's razor and claim a pure and powerful access to the emotions. Such was the case as the experimental work of Sherrington (1906) and Cannon (1914) were used to discredit James and replace his theory with single foundation in neurophysiology. The senses were, then, epiphenomenal - simply biological processes at a gross level of description. Further, the clinically oriented psychologists found that too much was sacrificed in Dynamic Psychology's translation of life urges into experimental abstractions. Thus, the journal Psychological Clinic contemptuously dismissed the volume as "brass instrument psychology," with the instruments "cunningly concealed" from the public. Finally, the Jamesian emphasis on sensations was difficult to cash out in terms of broader pragmatic demands. The invitation to polyphony was insufficient, then, to impede the rapacious discourse of behaviorism.

\section{Behaviorism and the sacrifice of emotion}

As broadly recognized, there was a close association between the ascendance of behaviorist psychology in the 1930s and the bold moves of philosophers of science toward foundations for a unified science (Koch, 1963). For academic psychologists in particular, the availability of principles of scientific rationality were particularly consequential. Still struggling for recognition and reputation, and unable to forge viable linkages among biological, human experimental, and practitioner enclaves, the possibility of modeling itself on a philosophically grounded model of science was an attractive one. Such a move would allow psychological inquiry to lay claim to independent scientific status. Because the conception of a unified science would ensure its connection to the natural sciences, no specific alliance with biology was essential. And because empiricist foundationalism gave hope that fundamental principles of human activity could be discovered, 
then any responsible clinical practice would necessarily be derived from the more basic science. In effect, there was a strong rationale for establishing psychology as an independent and basic science, from which could be developed a profusion of practical applications - in the clinic, schools, industry, the military, and so on. In retrospect, one must suppose that this family of arguments was a powerful one: Between 1930 and 1960 the ranks of the American Psychological Association expanded some twentyfold.

Yet, how were the emotions to be regarded by this foundational form of psychological science? To appreciate the fate of the emotions in this era, we must further consider the scientific model that psychologists appropriated from the philosophy of science. Central components of this received view were particular conceptions of observation, causality, and methodology. That which most clearly aligned the new psychology with the natural sciences was to be its emphasis on observables. Each of its theoretical conceptions, insofar as possible, was to be linked through a series of "operational definitions" to observable behaviors of the organism. In this way the discipline could replace the interminable and embarrassing imbroglios over the nature of the "inner world," with facts open to public observation and reliable replication. And, because overt behavior was clearly material, where "mindstuff" was dubitable at best, the discipline could claim ultimate unity with the natural sciences.

The centrality of observation was closely linked to a mechanical view of causality (Hollis, 1977). If the goal of the science is to predict the behavior of organisms, and the commitment to observation is preeminent, then the favored explanatory model is that of Humean causality: behavior as a consequence of observable antecedents. Teleology and intentionality, as alternative explanatory forms, are rendered suspect because of their necessary reference to inner (nonobservable) impulses. And, with mechanical causality as the strong preference for the new science, the optimal research method is experimentation. It is only in the context of the laboratory experiment, in particular, that the scientist can systematically control the antecedent conditions ("independent variables"), and trace their "causal effects," on behavioral outcomes ("dependent variables").

With these commitments in place, the fate of the emotions is virtually sealed. First, if the chief focus of the science is publicly observable behavior, then mental states and conditions are shunted to the margins of the discipline, at best "hypothetical," and at worst obfuscating folklore. Because the emotions are commonly viewed as constituents of the subjective world (the metaphor of inner sense), their status as "objects of study" is threatened. And, if they are primarily biological processes, as many argued, their status in psychological science is equally problematic. The prescribed forms of study in this case are primarily neurological and biochemical. Nor were the emotions easily absorbed into a science committed to a conception 
of mechanical causation. Theorists did argue that emotions are "triggered" by environmental stimuli, but on most traditional accounts the emotions themselves are inherent or instinctual. For example, if emotions are vital life forces with the capacity to drive or motivate thought and action, they function as unmoved movers. They are outside the system of antecedentconsequent contingency. One might observe their effects in natural settings, or compare the emotional tendencies of various species, but these are scarcely inviting topics for laboratory experimentation. In effect, with the assent of behaviorism the emotions largely vanished from the agenda of scientific psychology.

For radical behaviorists such as B. F. Skinner (1938), all mental state terms could properly be eradicated from the discipline. For more liberal behaviorists, the emotions made but fleeting entry into professional consciousness. For example, in F. H. Allport's volume, Social Psychology (1924), considered by many to have shaped the next 30 years of social psychological research, only 15 of the 453 pages are devoted to "feelings and emotion." Further, the treatment is primarily couched in terms of the biological metaphor. As to the origin of "feelings," Allport proposes, "The cranio-sacral division of the autonomic nervous system, supplemented under certain conditions by the cerebro-spinal system, innervates those responses whose return afferent impulses are associated with the conscious quality of pleasantness. The sympathetic division produces visceral responses which are represented in the consciousness as unpleasantness" ( $p$. 90). Much the same view is taken in Myerson's volume, Social Psychology, published ten years later. No chapter is given over to the emotions in social life, and the few relevant pages of the volume are built around the view that "the expression of emotion in the sense of the enormous changes which take place and become visible as rage, fear, etc. and which come to consciousness as the affect, arise largely through the hypothalamus" (p. 158). In the highly popular and more cognitively oriented text of the 1950s, Krech and Crutchfield's Theory and Problems of Social Psychology, there is no organized treatment of emotion; it is simply a term associated in unsystematic fashion to the concept of motivation.

\section{Neobehaviorism and the return of the interior}

The reasons for the softening grasp of radical behaviorism on psychological science are many and complex. However, as Koch (1963) outlines the case, psychologists themselves found the demands of a rigorous positivism too restrictive. Broad debate over the problems inherent in a strict operationalism, for example, led to a liberalization of views. Strong cases were made in favor of a family of "hypothetical constructs," terms that stood in for possible psychological processes but were not to be confused with the 
processes themselves. The chief function of such terms was to link independent and dependent variables in a systematic way. This liberalization of behaviorism - or the emergence of neobehaviorism - opened a respectable way for psychology to readmit the psychological interior to the science.

Perhaps the pivotal work for mainstream psychology was that of Clark Hull and his colleagues at Yale's Institute for Human Relations. Hull's careful and intellectually commanding work served as a model for psychology as science. His quasi-mathematical formulations for a theory of learning incorporated an increasing number of formal terms for a hypothetical interior. And, while there was no scientific purpose served by freighting such terms with cultural content, the possibility of a distinctly psychological treatment of the emotions was slowly reawakened when Hull articulated a concept of primary drive in his widely heralded, Principles of Behavior. Although primarily interested in the organism's acquisition of behavior patterns, Hull required an explanation for the organism's state of basic activation. This was accomplished first by borrowing from the biological metaphor the concept of tissue needs necessary for survival. The choice of a needs discourse was particularly auspicious, in this case, because needs, as opposed, for example, to instincts, can be related to environmental conditions ("hunger needs can be sated"), and the model thus retained an allegiance to the mechanistic metatheory. At the same time, however, Hull set out to establish a fully psychological theory. Thus, needs at the biological level were reinscribed as drives at the psychological level. Primary drives were thus based on a few simple organismic needs (hunger, thirst, pain avoidance, etc.), but, once placed into theoretical orbit, operated with explanatory efficacy without further reference to biological conditions.

While drawing sustenance from the biological metaphor, the conception of primary drive also carries strong traces of the romanticist metaphor of vital energy. By successfully exploiting this tradition, psychoanalysts had successfully ensconced themselves within the medical profession. However, with the concept of drive now granted scientific respectability, the door was open not only for scientific psychology to reclaim the discourse of emotion, but for appropriating psychoanalytic formulations - of demonstrating that the basic tenets of psychoanalytic theory were consistent with the more scientifically well grounded theories of neobehaviorism. The most significant attempt of this kind was Dollard and Miller's 1950 volume, Personality and Psychotherapy. As these authors proposed, by drawing on the energic wellsprings of the primary drives, new dispositions (secondary drives) could - under a particular combination of antecedent conditions be established. Thus, for example, fear is "an innate response to a (pain) stimulus" (p. 69). However, if the painful stimulus is associated with a previously neutral cue, the neutral cue will come to produce fear (now a 
secondary drive). By extending assumptions such as these, psychotherapy can be properly envisioned as a form of learning laboratory.

With this opening for the development of emotionlike constructs in scientific psychology, the metaphor of emotion as driving force was reinscribed in dozens of volumes, including Young's Motivation and Emotion, Symonds's Dynamic Psychology, Leeper and Madison's Understanding Personality, and Cofer's Motivation and Emotion. Such volumes succeeded in tracing the major Freudian concepts - along with a broad array of common emotion terms (including love) - to a drive formulation. Yet, the monophonic claim to superiority also stood as a challenge to those invested in alternative discourses. If the emotions were now legitimate objects of study, there were other long-standing metaphors to which allegiance could be claimed. The old battle lines were soon reactivated. In 1964, D. E. Berlyne was given the opportunity to inscribe the first chapter on emotions ever to appear in the prestigious Annual Review of Psychology. The title of this entry into the 15th volume of the series, "Emotional Aspects of Learning," seems to leave the behaviorist imprimatur unquestioned. As Berlyne begins, "Psychologists are, on the whole, following a suggestion reiterated since 1934 by Duffy. She contended that terms like 'emotion' have outlived their usefulness. We should, she feels, give them up and recognize that all behavior, including 'emotional' behavior, has both a 'directive' aspect and an 'energy-mobilization' (or to use newer terms, 'activation' or 'arousal') aspect, with distinguishable determinants" (p. 115). Berlyne concurs with this view, but through a series of subtle interpolations, points the way to replacing the metaphor of driving force with a physiological discourse.

As Berlyne reasons, if emotions are essentially internal drives, and drives are fundamentally biological, then neurological investigation of brain stimulation constitutes a contribution to our understanding of emotion. By then reviewing research on the reticular formation, the limbic system, and the lateral hypothalamus as they "arouse" the organism, the way was again opened to replace "drive" with physiology. And when physiology becomes the basis of learning, then psychological theorizing about learning becomes superfluous. Behaviorist theory is placed in jeopardy; the physiological metaphor is resuscitated. Further conflict, however, would be postponed until the cognitive movement reached maturity.

\section{The cognitive revolution: Suppression and suspiration}

With interior process once again reinstated, the neobehaviorist program was slowly eclipsed by a broad and enthusiastic resuscitation of mental discourse - particularly the discourse of reason. Although there are many reasons for what became known as the "cognitive revolution" in psychology, just as in the case of behaviorism, this investment can be traced in part 
to psychology's dependency on a philosophy of science with its major roots in the Enlightenment. The twin philosophical movements on which Enlightenment epistemology largely rests are the empiricist and rationalist. Empiricist philosophy of science (drawing from Locke, Hume, and the Mills) gives primary voice to the former (e.g., the preeminent role of observation), whereas the rationalist tradition (drawing from Descartes, Leibniz, and Kant) is placed in a secondary but nevertheless essential position (e.g., the role of induction and deduction). In many respects, the behaviorist and neobehaviorist movements in psychology recapitulate at the theoretical level the empiricist emphasis in the philosophy of science. That is, the theories of human psychology represent reformulations of the empiricist metatheory that informs the behaviorist and neobehaviorist projects of science (Gergen, 1994). However, these movements simultaneously left unexplored the rationalist contribution to the reigning metatheory. Unexplored was the implicit implicature, in which rational processes could be credited with a contribution to human action - not simply pawns to antecedent conditions, but possessing intrinsic properties with their own demands on action. Thus, the drama of Piaget's (1952) genetic epistemology, Chomsky's (1958) critique of the Skinnerian theory of language, and his subsequent advocacy of inherent syntactical knowledge (Chomsky, 1968) was a significant demotion in the causal powers attributed to "the stimulus world." These theories granted active mental operations the central role in directing human action. The floodgates were now open, and the literature soon abounded in research and theory on intrinsic cognitive process.

In terms of inquiry into the emotions, however, the initial effect of the cognitive movement was full-scale suppression. To render the ontology of "cognition" both intelligible and compelling favored a family of metaphors that either obscured or failed to recognize a domain of emotions. Although centrally concerned with the problem of "mental representation," the traditional epistemological metaphor of "mind as mirror" (Rorty, 1979) was unserviceable. The metaphor again granted too much credit to the demands of the stimulus world. Rather, cognitive theorists required fresh metaphors - and particularly those which could grasp the imagination of the scientific community. It is thus that much cognitive theory incorporated, for example, the metaphor of rationality as statistical process; when operating optimally, rational thought approximated the principles of statistical analysis (see Gigerenzer and Murray, 1987). Also compelling was a family of metaphors drawn from engineering (servomechanisms, feedback loops, networks) and physics (the hologram). However, perhaps the dominant metaphor for the cognitive theorist, and one that adds the strength of allegiance to the field of artificial intelligence, is the computer (see Hoffman, Cochran, and Nead's 1990 review). When the internal world is constituted by computational devices, addresses, locations, data structures, formats, and other 
forms of information processing, the emotions are erased from the ontology of the interior. Thus, between Berlyn's 1964 entry and 1986, not a single chapter on the emotions appeared in the Annual Review of Psychology.

Yet, a psychology without emotion would not only fail to draw public advantage from this symbolic capital but, more locally, would reduce the dependency of clinical practitioners on "mainstream" science. The major challenge, then, was to develop a theory that would allow the emotions to be appropriated by cognitive theory. This was furnished by Stanley Schachter's (Schachter, 1964; Schachter and Singer, 1962) two-factor theory of emotion. Schachter's formulation carried the traces of both the James and Hull formulations. Like James, he cleanly separated biology from psychology. At the same time he was able successfully to reframe the sensory metaphor. Rather than viewing conscious experience as a passive recording (in this case of the biological interior), the psyche was granted status as an active interpreter of the world and self. Cognitive process did not so much reflect as determine the nature of emotional experience. Similar to Hull, Schachter resorted to an amorphous concept of undifferentiated arousal. In effect, the biological system furnished energy in the form of generalized activation, and the cognitive system (rather than sensing messages from biology as in the case of James) operated in a "top down" manner to define its character. For Schachter (1964), cognition "exerts a steering function. ... It is the cognition which determines whether the state of physiological arousal will be labeled 'anger,' 'joy,' or whatever" (p. 51).

Not only did Schachter's polyphonic account open up a means for cognitive theorists to annex an important discourse - without threatening the preferred explanatory fulcrum - but it also promised riches in practical/ therapeutic application. Of particular importance was the conception of cognitive attribution. Thus, rather than treating actual states of emotion, motivation, pain, and the like, these states were deontologized, and the practitioner was invited to focus on attributional tendencies or styles. Under what conditions did the individual attribute pain, anger, romantic love, and so on to the self, and how could therapists help the client to reconceptualize these conditions in more promising ways. (See, e.g., Harvey and Ickes, 1976; Harvey and Weary, 1985.) Perhaps the most articulate application of the cognitive perspective to psychotherapy is contained in Aaron Beck's (1976) Cognitive Therapy and the Emotional Disorders. Published almost 15 years after the initial appearance of Schachter's work, Beck's study alters the explanatory structure, so that the individual does not cognize undifferentiated arousal (a view that had come under considerable attack) but cognizes the situation. It is this cognition that has an automatic eliciting effect on the emotional response. "The thesis that the special meaning of an event determines the emotional response forms the core of the cognitive model of emotions and emotional disorder. The meaning is encased in 
cognition" (p. 52). In effect, while a biological propensity is recognized, cognitive process remains regnant.

In many respects, Schachter's theory did much the same as William James's at the turn of the century to generate a vision of unification among psychologists, biologists, and the mental health practitioners - yet, with psychology firmly at the helm. Also similar to James, this vision was not to be realized. Schachter's polyphonic account not only brought emotions into the analytic eye once again but also the residual traces of competing metaphors. The turn-of-the-century metaphors had scarcely been lost; they were not only present in the common vernacular, but various professional enclaves (e.g., comparative psychologists, psychobiologists, ethological psychologists) had continued to elaborate their potentials outside the mainstream. These enclaves, were also energized by the cognitivists' penchant for removing the emotions from the ledger. It was with a sense of righteous indignation - and possibly an eye toward establishing a unique professional profile - that the earlier metaphors were once again resuscitated. Leventhal and Tomarken's (1986) chapter in the Annual Review of Psychology, "Emotion: Today's Problems," is illustrative:

Much of the conflict and confusion in this area stems from an unwillingness to grant independent conceptual status to emotion. This "begrudging" attitude has three components: (a) the behavioristic legacy and its suspicion of subjective concepts; (b) the traditional cognitive hold on our thinking in which emotion is a combination of arousal and cognition . . ; and (c) the reluctance of cognitively oriented scientists to view an emotion as anything more complex than a "stop" or interrupt rule in the simulation of mental operations. . . Admitting a richer concept of emotion to the lexicon could generate major upheavals in cognitive theory as emotions theory addresses the growing theoretical and empirical knowledge in neuroscience and molecular biology. (p. 566)

With this concluding sentence, the biological metaphor again springs to life. Support is garnered in this case from a variety of studies in brain lateralization. Research is used to argue that the right cortical hemisphere plays a major role in the control and expression of moods, and the recognition of emotion in others. The left hemisphere is said to be "nonemotional" (Tucker, 1981). It was noted earlier that the biological metaphor could be segmented, the one viewing emotions as physiological events and the other as animal behavior. Armed with the second metaphor, another phalanx of investigators attempted to identify emotions as intrinsic patterns of organismic expression. Perhaps the most widely heralded of these endeavors are those of Paul Ekman and his colleagues, who - following in Darwin's footsteps - amassed data to prove that the expression of "the basic" emotions in human beings is universal (Ekman, 1982). These efforts were also supported by animal behavior specialists who argued for the evolutionary benefits derived from various emotional expressions (cf. Eibel-Eibelsfeldt, 1979; Plutchick, 1980). The two biological metaphors are finally collapsed - 
or at least, a harmony is sought - in the Blanchard and Blanchard's contribution to the 1988 volume of the Annual Review of Psychology.

The drive energy metaphor has also reappeared in full regalia. This is unabashedly so in the therapeutic community, where popular-selling volumes on the primal scream, cocounseling, and 12-step programs celebrate the elemental force of the emotions. More subtly, the metaphor has resurfaced in a number of scholarly treatises attempting not so much to replace the cognitive and the biological views, as to perform interpolations in which motivational forces are given a primary role. For example, in the broad overview of Frijda (1986), the emotions are treated as forms of action potential (with traces of unleashed drives). "The emotions," he writes, "can be defined as modes of relational action readiness, either in the form of tendencies to establish, maintain, or disrupt a relationship with the environment or in the form of modes of relational readiness as such" (p. 71). Similarly, in his elaborate integration of the literature, Lazarus (1991) not only stresses the concept of emotion as motivation (drawing from the seventeenth-century concept of the passions), but posits a vast array of innate "action tendencies" that determine the course of anger, envy, love, sadness and so on.

Thus, in spite of the generalized hegemony of the cognitive movement, we find that as emotion has returned full force as a discursive object, the profession is once again fragmented. The fault lines are precisely those of the century's beginning. Differing camps construct research programs, generate literatures, hold conferences, and generally organize themselves around contrasting tropes. Illustrative of this climate of contestation is George Mandler's (1984) troubled query,

Is there a cohesive psychology of emotion? . . It may be symptomatic that the best summary was provided by Madison Bentley. He knew in 1928 what too many psychologists still fail to accept today, that there is no commonly, even superficially, acceptable definition of what a psychology of emotion is about. . . . Bentley concludes: "Whether the term (emotion) stands for a psychological entity upon which we are all researching I do not know. Whether it is the common subject of our varied investigations I am not sure enough to be dogmatic." (p. 16)

\section{Social constructionism and the metaphoric inflection}

Thus far we find that as various movements in psychology have gained ascendance - within the discipline, within the academy more generally, or within the broader cultural and economic context of mental health practice - emotional discourse has been shaped or suppressed accordingly. The different metaphors of the emotions have variously served to justify, credit, excoriate, build allegiances, sustain effective relations, and secure employment for a broad array of disciplinary subcultures. Abundant traces of earlier contests remain, as discursive regimes wax and wane in strength. 
However, the story does not thereby terminate. There is yet a final chapter to be added, one that dramatically alters the rhetorical landscape. We confront now the possible emergence of a new form of monophony.

For early behaviorists, the absence of research on emotions seemed largely derived from a commitment to a logical empiricist metatheory. However, since the 1950s logical empiricist philosophy has become subject to increasing criticism, and since the 1960s there has been a general erosion of interest in projects designed to establish rational foundations of scientific method. Moving from the more conservative critiques, for example, of Popper and Quine, to the more radical incursions of theorists such as Kuhn and Feyerabend, philosophy has entered what most consider a "postempiricist" phase. This erosion of confidence in the philosophical justification for scientific psychology has also invited a broad-scale critique of the science and fostered lively discussion of a "new psychology."1

As many now recognize, perhaps the chief contender for a successor project to logical empiricism is some form of social constructionism. Drawing importantly from emerging developments most prominently in the history of science, the sociology of knowledge, ethnomethodology, rhetorical studies of science, symbolic anthropology, feminist theory, and poststructuralist literary theory, social constructionism is not so much a foundational theory of knowledge as an antifoundational dialogue. Primary emphases of this dialogue are placed on the social-discursive matrix from which knowledge claims emerge and from which their justification is derived; the values/ ideology implicit within knowledge posits; the modes of informal and institutional life sustained and replenished by ontological and epistemological commitments; and the distribution of power and privilege favored by disciplinary beliefs. Much attention is also given to the creation and transformation of cultural constructions; the adjudication of competing belief/value systems; and the generation of new modes of pedagogy, scholarly expression, and disciplinary relations.

Given these investments - in loosening the grip of the empiricist world view, and building toward a positive alternative - what posture can constructionist psychologists take toward the emotions? In this instance none of the central metaphors of the preceding century are felicitous. The biological, the sensory (and its cognitive derivative), and the energic metaphors each conflict with the assumptions of constructionist metatheory. The earlier metaphors, instantiated at the theoretical level, blunt the impetus toward change at the level of metatheory. To enumerate the most prominent failings: (1) Each of the traditional metaphors essentializes the emotions treating them as biological, sensory-cognitive, or energic givens - there in nature, to be interrogated by science. In effect, the metaphors portend the existence of an obdurate domain outside the realm of social construction. (2) Each metaphor derives from and rationalizes a dualistic conception of 
human functioning. Not only is dualism a primary constituent of the empiricist view of knowledge (with the mental representations of individuals serving as the locus of knowledge), but favors psychological explanations of human action as opposed to the microsocial explanations central to constructionism. (3) In their focus on individual process, each of the metaphors favors an ideology of the self-contained individual, a commitment that most constructionists see as inimical to cultural well-being. Feminist critics have been particularly vocal in their critiques of the biological metaphor, and its contribution to the cluster of androcentric binaries that valorize reason, culture, and masculinity, at the expense of emotion, nature, and femininity.

Confronted with the unattractive options offered by the tradition, and desirous of appropriating this significant discursive realm, it has been necessary for constructionists to draw from alternative repositories of cultural intelligibility. The result is a resuscitation of a family of interrelated but (until now) more marginal metaphors within the culture. Primary among these are life as theater (the dramaturgic), as game (the ludic), as literature (the narrative), and as cultural ritual (the tribal). These metaphors not only furnish the constructionist with a novel and intelligible set of alternatives to the discourses favored by empiricist psychology, but simultaneously function to reinforce the social constructionist alternative to empiricist metatheory. The metaphors thus carry a dual function, serving as explanatory vehicles in scholarly research on the emotions, and as rhetorical supports for the overarching attempts at metatheoretical ascendance.

To elaborate, each of the new metaphors first draws attention away from individual, psychological process, and gives primacy to the social sphere: to the play (see, e.g., Sarbin, 1986; Averill, 1982), the game (Bailey, 1983), the text (Gergen and Gergen, 1988), or the tribal ritual (Rosaldo, 1980; White and Kirkpatrick, 1985). In effect, psychological explanations are replaced by processes of cultural meaning-making. Second, the kind of essentialism posited by the empiricists is placed in critical relief, as each of the metaphors views the emotions as socially constituted - with emotional action paralleling, for example, the performance of Hamlet (the dramaturgic), or hitting a "home run" in baseball (the ludic); to achieve an emotion is thus similar to writing a climax to a short story (the narrative), or participating in a rite de passage (the tribal). There simply is no reality of emotion independent of the community of interlocutors.

Further, each of these metaphors operates against the empiricist claims of universality - casting aspersions on formulations of human functioning that discount history and culture. Rather, each invites sensitivity to the sociocultural circumstances giving rise to various forms of emotional performance. Constructionist scholarship thus lays special emphasis on the specific cultural functions played by various emotional expressions (see, e.g., Lutz, 1988), and the historical conditions giving rise to various forms of 
emotion (Badinter, 1980; Stearns, 1989). Finally, each of these metaphors opens the way to social critique. The empiricist family of metaphors was all consistent with a world of Humean causality; individual behavior is simply a causal byproduct of antecedent conditions (physiology, stimuli, human constitution). Persons themselves have no responsibility for their actions. For constructionists, such a view of human action not only favors the status quo ("people simply do what they must do"), but leads to myopic claims of ethical neutrality. Yet, the alternative metaphors of the stage, the game, the text, and the tribe all emphasize the optional nature of the actions in question. Contemporary patterns of action are scarcely required, and they could be otherwise (see, e.g., Lutz and Abu-Lughod, 1990). Further, it is one of the responsibilities of the scholar to challenge problematic patterns of action, to engage in forms of social critique.

\section{Conclusion}

The view of a unitary hegemonic discourse, subtly expanding and subverting alternative intelligibilities, scarcely fits the history of American psychology. Rather, we find a discipline that is at once attempting to legitimate itself with respect to differing audiences (the academic and the general populace in particular), and fraught with internecine warfare concerning the image of science. Further, these investments are significantly manifest in the theoretical content of the field. As emphasized here, the view taken of "the emotions" is scarcely neutral - derived from a preexistent observation base - but plays an important role in the varying attempts at professional ascendance. The metaphoric construction of the emotions thus serves to buttress or reinforce claims to legitimacy. In certain cases, claims to superior position have lent themselves to theories that exclude or marginalize emotions discourse. However, because "the emotions" are integral to the culturally sedimented belief systems, exclusionary projects are limited in life-span. They are vulnerable to competing movements that, by reinstating the emotions, gain important cultural advantage. There is, then, substantial institutional power derived from compelling metaphors of the emotions. While various movements in psychology have attempted to eradicate the emotions, the resilience and resurgence of the discourse reveals the overarching significance of the broader context of meaning.

Further, when emotions discourse has played a central role in justifying the scientific project, it has confronted an obfuscating polyphony. A variety of compelling metaphors has been available for elaboration. However, attempts at a polyphonic blending have not sutured the conflicting figurations. And, with variegated metaphors still creditable, the temptation toward monophonic reductionism remains ever salient. The move toward a social constructionist science significantly alters the political complex. Construc- 
tionists abandon each of the traditional metaphors - and thus both the long-standing tendencies toward polyphony and monophony. Rather, the constructionist relies on a family of textually related metaphors that blur the distinction between polyphony and monophony. And, while these metaphors are not likely to carry rhetorical weight within the natural science domain, they are highly congenial with the shift toward a human (as opposed to a behavioral) science more generally within the academy. We thus confront a new array of tensions, the results of which are certain to ramify throughout forthcoming disquisitions on emotion.

\section{Note}

1 See, for example, Armistead (1974), Harre and Secord (1972), and Gergen (1994a).

\section{References}

Allport, F. H. (1924) Social psychology. New York: Houghton Mifflin.

Anscombe, G. E. M. (1976) Intention. Oxford: Blackwell.

Armistead, N. (Ed.) (1974) Reconstructing social psychology. Baltimore: Penguin.

Austin, J. L. (1962) Sense and sensibilia. London: Oxford University Press.

Averill, J. R. (1982) Anger and aggression: An essay on emotion. New York: Springer-Verlag. Averill, J. R. (1990) Inner feelings, works of the flesh, the beast within, diseases of the mind, driving force, and putting on a show: Six metaphors of emotion and their theoretical extensions. In D. E. Leary (Ed.), Metaphors in the history of psychology. Cambridge: Cambridge University Press, pp. 104-132.

Badinter, E. (1980) Mother love, myth and reality. New York: Macmillan.

Bailey, F. G. (1983) The tactical uses of passion. Ithaca, NY: Cornell University Press.

Bakhtin, M. (1981) The dialogic imagination. Austin: University of Texas Press.

Beck, A. T. (1976) Cognitive therapy and the emotional disorders. New York: Meridian.

Berlyne, D. E. (1964) Emotional aspects of learning. In Annual Review of Psychology. Palo Alto: Annual Reviews.

Blanchard, C. C., and Blanchard, R. J. (1988) Ethoexperimental approaches to the biology of emotion. In Annual Review of Psychology. Palo Alto: Annual Reviews.

Cannon, W. B. (1914) The interrelations of emotions as suggested by recent psychological researches. American Journal of Psychology, 25, 256-282.

Chomsky, N. (1959) A review of B. F. Skinner's Verbal behavior. Language, 35, 26-58.

Chomsky, N. (1968) Language and mind. New York: Harcourt, Brace and World.

Cofer, C. (1972) Motivation and emotion. Glencoe, IL: Scott Foresman.

Derrida, J. (1976) Of grammatology. Baltimore: Johns Hopkins University Press.

Dollard, J., and Miller, N. (1950) Personality and psychotherapy. New York: McGraw-Hill.

Eibel-Eibelsfeldt, I. (1979) Love and hate. New York: Holt, Rinehart and Winston.

Ekman, P. (Ed.) (1982) Emotion in the human face. Cambridge: Cambridge University Press.

Foucault, M. (1978) The history of sexuality, Vol. 1. New York: Pantheon.

Foucault, M. (1979) Discipline and punish: The birth of the prison. Trans. A. Sheridan. New York: Vintage.

Frijda, N. H. (1986) The emotions. Cambridge: Cambridge University Press.

Gergen, K. J. (1993) Textual considerations in the scientific construction of human character. In J. V. Knapp (Ed.), Literary character. Lanham, MD.: University Press of America, pp. $365-379$.

Gergen, K. J. (1994) Toward transformation in social knowledge, 2nd ed. London: Sage. 
Gergen, K. J. (1994a) Realities and relationships: Soundings in social construction. Cambridge, MA: Harvard University Press.

Gergen, K. J., and Gergen, M. M. (1988) Narratives and the self as relationship. In L. Berkowitz (Ed.), Advances in experimental social psychology, Vol. 21. New York: Academic Press, pp. 17-66.

Gigerenzer, G., and Murray, D. J. (1987) Cognition as intuitive statistics. Hillsdale, NJ: Erlbaum.

Harre, R., and Secord, P. F. (1972) The explanation of social behaviour. Oxford: Blackwell.

Harvey, J. H., and Ickes, W. J. (Eds.) (1976) New directions in attribution research. New York: Halstead.

Harvey, J. H., and Weary, G. (Eds.) (1985) Attribution: Basic issues and applications. Orlando, FL: Academic Press.

Hoffman, R. R., Cochran, E. L., and Nead, J. M. (1990) Cognitive metaphors in experimental psychology. In D. E. Leary (Ed.), Metaphors in the history of psychology. Cambridge: Cambridge University Press.

Hollis, M. (1977) Models of man. Cambridge: Cambridge University Press.

Izard, C. E. (1977) Human emotions. New York: Plenum.

James, W. (1890) Principles of psychology, Vol. 1. New York: Henry Holt.

Kenny, A. (1963) Action, emotion and will. London: Routledge and Kegan Paul.

Koch, S. (1963) Epilogue. In S. Koch (Ed.), Psychology: A study of a science, Vol. 3. New York: McGraw-Hill, pp. 411-491.

Krech, D., and Crutchfield, R. S. (1948) Theory and problems of social psychology. New York: McGraw-Hill.

Lazarus, R. S. (1991) Emotion and adaptation. New York: Oxford University Press.

Leeper, R. N., and Madison, P. (1959) Toward understanding personality. New York: Appleton-Century-Crofts.

Leventhal, H., and Tomarken, A. J. (1986) Emotion: Today's problems. In Annual review of psychology. Palo Alto: Annual Reviews.

Lutz, C. (1988) Unnatural emotions. Chicago: University of Chicago Press.

Lutz, C., and Abu-Lughod, L. (1990) Language and the politics of emotion. Cambridge: Cambridge University Press.

Mandler, G. (1984) Mind and body: Psychology of emotion and stress. New York: Norton.

Manicas, P. T. (1987) A history and philosophy of the social sciences. Oxford: Blackwell.

Myerson, A. (1934) Social psychology. New York: Prentice-Hall.

Oatley, K., and Jenkins, J. M. (1992) Human emotions: Function and dysfunction. In Annual review of psychology. Palo Alto: Annual Reviews.

Piaget, J. (1952) The origins of intelligence in children. New York: Norton.

Plutchik, R. (1980) A general psychoevolutionary theory of emotion. In R. Plutchik and H. Kellerman (Eds.), Emotion, theory research and experience. New York: Academic Press.

Rorty, R. (1979) Philosophy and the mirror of nature. Princeton: Princeton University Press.

Rosaldo, M. (1980) Knowledge and passion. Cambridge: Cambridge University Press.

Rose, N. (1985) The psychological complex. London: Routledge and Kegan Paul.

Rose, N. (1990) Governing the soul. London: Routledge.

Ryle, G. (1949) The concept of mind. London: Hutchinson.

Sarbin, T. R. (1986) Emotion and act: Roles and rhetoric. In R. Harre (Ed.), The social construction of emotions. Oxford: Blackwell, pp. 211-239.

Schachter, S. (1964) The interaction of cognitive and physiological determinants of emotional state. In L. Berkowitz (Ed.), Advances in experimental social psychology, Vol. 1. New York: Academic Press, pp. 379-399.

Schachter, S., and Singer, J. (1962) Cognitive, social and physiological determinants of emotional state. Psychological Review, 69, 379-399.

Sherrington, C. S. (1906) The integrative action of the nervous system. New Haven: Yale University Press. 
Skinner, B. B. (1938) The behavior of organisms: An experimental analysis. New York: Appleton-Century-Crofts.

Stearns, P. N. (1989) Jealousy: The evolution of an emotion in American history. New York: New York University Press.

Symonds, P. M. (1949) Dynamic psychology. New York: Appleton-Century-Crofts.

Tomkins, S. (1962) Affect, imagery, and consciousness, Vol. 1. New York: Springer.

Tucker, D. M. (1981) Lateral brain function, emotion, and conceptualization. Psychological Bulletin, 89, 19-46.

White, G., and Kirkpatrick, J. (Eds.) (1985) Person, self and experience: Exploring Pacific ethnopsychologies. Berkeley: University of California Press.

Williams, R. (1980) Problems in materialism and culture. London: Verso.

Wittgenstein, L. (1978) Philosophical investigations. Oxford: Blackwell.

Wittgenstein, L. (1980) Remarks on the philosophy of psychology. Ed. G. H. von Wright and H. Nyman. Oxford: Blackwell.

Woodworth, R. S. (1918) Dynamic psychology. New York: Columbia University Press.

Young, P. T. (1961) Motivation and emotion: A survey of the determinants of human and animal activity. New York: Wiley. 